\title{
Determinants of fetal haemoglobin in newborn infants
}

\author{
D G Fagan, R J Lancashire, A Walker, T Sorahan
}

Department of Histopathology, University Hospital, Nottingham NG7 2UH D G Fagan

Department of Public Health and

Epidemiology,

University of

Birmingham

R J Lancashire

T Sorahan

Department of

Haematology,

University Hospital,

Nottingham

A Walker

Correspondence to:

Dr Fagan.

Accepted 5 November 1994

\begin{abstract}
Percentage fetal haemoglobins (\% HbF) were measured in 7081 newborns at the University Hospital, Nottingham, between 1990 and 1992 to assess the effects of a range of factors, and to determine if there was an association between \% $\mathrm{HbF}$ at birth and risk of SIDS (sudden infant death syndrome). Data from the obstetric clinical records were analysed by multiple linear regression to establish the major determinants of $\%$ HbF. New findings were the identification of maternal smoking, twin pregnancy, ethnic origin, and season of birth as significant determinants. Alcohol use, drug and vitamin intake, and duration of labour were not found to be important. The previously reported correlations between $\%$ HbF and sex, gestational age, and birthweight were confirmed, and the relative effects quantified. Overall, the major determinants of an increase in $\% \mathrm{HbF}$ in neonates are similar to the known antenatal risk factors for sudden infant death syndrome (SIDS).

(Arch Dis Child 1995; 72: F111-F114)
\end{abstract}

Keywords: fetal haemoglobin, newborns, determinants, SIDS.

Table 1 Population statistics and mean \% fetal haemoglobin for 7081 babies by levels of maternal and infant factors

\begin{tabular}{|c|c|c|c|c|}
\hline Variable & $n=\star$ & $\% H b F$ & $S D$ & SEM \\
\hline \multicolumn{5}{|l|}{ Infant factors } \\
\hline \\
\hline $\begin{array}{l}\text { Male } \\
\text { Female }\end{array}$ & $\begin{array}{l}3690 \\
3391\end{array}$ & $\begin{array}{l}78 \cdot 07 \\
76 \cdot 62\end{array}$ & $\begin{array}{l}7 \cdot 01 \\
7 \cdot 40\end{array}$ & $\begin{array}{l}0 \cdot 12 \\
0.13\end{array}$ \\
\hline \multicolumn{5}{|l|}{ Birthweight (kg) } \\
\hline $\begin{aligned}<2.50 \\
2.50-2.99 \\
3.00-3.49 \\
\geqslant 3.50\end{aligned}$ & $\begin{array}{r}409 \\
1227 \\
2660 \\
2781\end{array}$ & $\begin{array}{l}84 \cdot 26 \\
79 \cdot 37 \\
77 \cdot 14 \\
75 \cdot 71\end{array}$ & $\begin{array}{l}6 \cdot 94 \\
7 \cdot 03 \\
6 \cdot 78 \\
6 \cdot 97\end{array}$ & $\begin{array}{l}0.34 \\
0 \cdot 20 \\
0 \cdot 13 \\
0 \cdot 13\end{array}$ \\
\hline \multicolumn{5}{|l|}{ Ethnic group } \\
\hline Caucasian & 6202 & $77 \cdot 60$ & $7 \cdot 07$ & 0.09 \\
\hline Afro-Caribbean & 240 & $77 \cdot 07$ & $7 \cdot 95$ & 0.51 \\
\hline Indo-European & 498 & $74 \cdot 60$ & $8 \cdot 05$ & 0.36 \\
\hline Arabic/Oriental/other & 141 & $77 \cdot 75$ & $8 \cdot 00$ & 0.67 \\
\hline \multicolumn{5}{|l|}{ Singleton/twin } \\
\hline $\begin{array}{l}\text { Singleton } \\
\text { Twin }\end{array}$ & $\begin{array}{r}6933 \\
148\end{array}$ & $\begin{array}{l}77 \cdot 23 \\
84 \cdot 00\end{array}$ & $\begin{array}{l}7 \cdot 21 \\
4 \cdot 99\end{array}$ & $\begin{array}{l}0.09 \\
0.41\end{array}$ \\
\hline \multicolumn{5}{|l|}{ Period of deliveryt } \\
\hline $\begin{array}{l}\text { June 1990-August } 1991 \\
\text { February 1992-October } 1992\end{array}$ & $\begin{array}{l}4857 \\
2224\end{array}$ & $\begin{array}{l}76 \cdot 72 \\
78 \cdot 80\end{array}$ & $\begin{array}{l}6 \cdot 97 \\
7 \cdot 58\end{array}$ & $\begin{array}{l}0 \cdot 10 \\
0 \cdot 16\end{array}$ \\
\hline \multicolumn{5}{|l|}{ Maternal factors during pregnancy } \\
\hline \multicolumn{5}{|l|}{ Cigarette smoking } \\
\hline $\begin{array}{l}\text { No } \\
\text { Yes }\end{array}$ & $\begin{array}{l}5123 \\
1902\end{array}$ & $\begin{array}{l}76.90 \\
78.61\end{array}$ & $\begin{array}{l}7 \cdot 26 \\
6 \cdot 92\end{array}$ & $\begin{array}{l}0 \cdot 10 \\
0.16\end{array}$ \\
\hline \multicolumn{5}{|l|}{ Alcohol use } \\
\hline $\begin{array}{l}\text { None } \\
\text { Some }\end{array}$ & $\begin{array}{l}4714 \\
2270\end{array}$ & $\begin{array}{l}77 \cdot 26 \\
77 \cdot 57\end{array}$ & $\begin{array}{l}7 \cdot 26 \\
7 \cdot 11\end{array}$ & $\begin{array}{l}0.11 \\
0.15\end{array}$ \\
\hline \multicolumn{5}{|l|}{ Drugs or vitamins taken } \\
\hline $\begin{array}{l}\text { No } \\
\text { Yes }\end{array}$ & $\begin{array}{r}6797 \\
284\end{array}$ & $\begin{array}{l}77 \cdot 37 \\
77 \cdot 45\end{array}$ & $\begin{array}{l}7 \cdot 20 \\
7 \cdot 85\end{array}$ & $\begin{array}{l}0.09 \\
0.47\end{array}$ \\
\hline
\end{tabular}

*Numbers of infants do not always equal 7081 because of missing values.

tA new instrument to measure HbF was introduced 1 October 1991.

Giulian et al reported startlingly high values of percentage fetal haemoglobin $(\% \mathrm{HbF})$ in infants dying from cot death. ${ }^{1}$ Fagan and Walker presented similar findings, showing raised values of $\% \mathrm{HbF}$ in sudden infant death syndrome (SIDS) but only when an appropriate gestationally matched control population was used. ${ }^{2}$ Significant differences between the postnatal decline in $\% \mathrm{HbF}$ in preterm and full term infants were also reported. ${ }^{2}$

The present study of $\% \mathrm{HbF}$ values in newborn infants was undertaken to establish normal values and ranges in newborns of different gestational ages, to assess the effects of fetal, maternal, environmental and ethnic factors, and to establish a cohort of infants for which the patterns of later disease, especially SIDS, could be examined in relation to $\% \mathrm{HbF}$ at birth. Results relating to the first two objectives are presented in this report.

The qualitative pattern of developmental changes in haemoglobin concentration during pregnancy is well known, ${ }^{3-5}$ but the quantitative measurement of $\mathrm{HbF}$ at different gestational ages is less well delineated. Two previous systematic surveys of haemoglobin in the late second and third trimesters of pregnancy measured adult haemoglobin $(\mathrm{HbA})$, and assumed that the remainder of the haemoglobin present was fetal. ${ }^{67}$ Most previous reports of normal values of $\% \mathrm{HbF}$ have been obtained from relatively small numbers of infants.

\section{Methods}

Cord blood samples were sought from all infants delivered at the University Hospital, Nottingham, from June 1990 to October 1992. The samples were taken in the delivery suite by midwives following the procedure used in the sickle cell screening programme - samples were taken by venesection of the umbilical cord shortly after delivery, using a needle and syringe. Samples were placed in a plastic sample tube with liquid Sequestrene anticoagulant and refrigerated at $+4^{\circ} \mathrm{C}$ for collection within 24 hours. Percentages of $\mathrm{HbF}$ in the samples were then measured.

The first half of the study was carried out using the apparatus described before. ${ }^{2}$ The spectrophotometer was then replaced by a Uvicon machine, working in batches of 10 using an automatic sampling device. The method of Jonxis and Huisman ${ }^{8}$ was used. ${ }^{2}$ As all the $\% \mathrm{HbF}$ values were expected to be high, only the method of Jonxis and Huisman was used. Controls were run on both machines, and the values obtained were within 


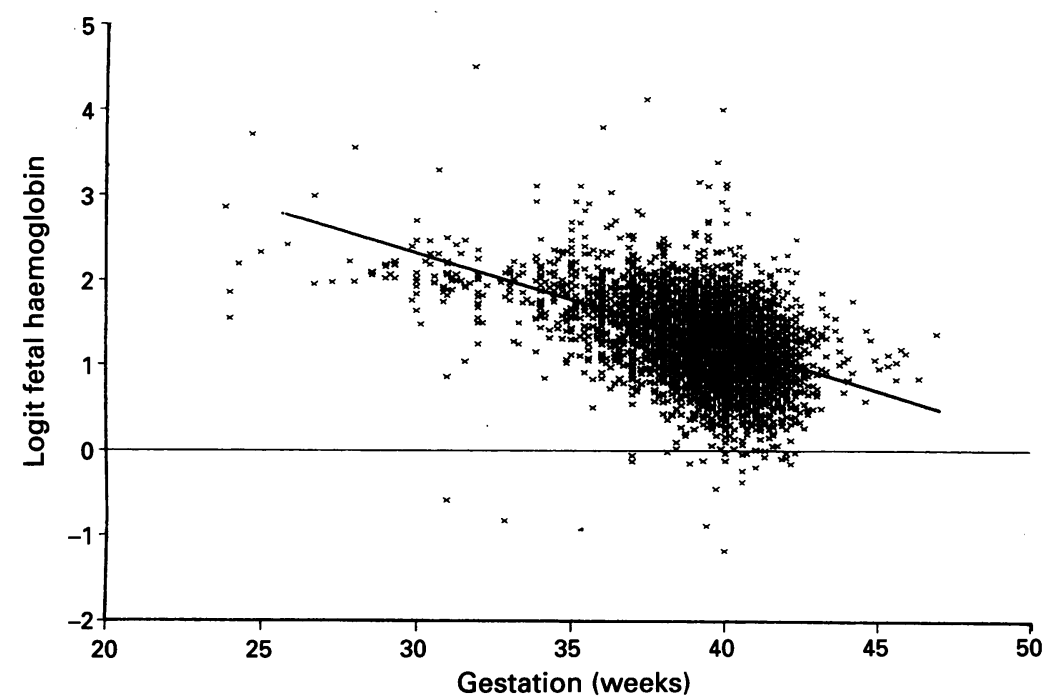

Figure $1 \% \mathrm{HbF}$ and logit (\% HbF) by gestation.

the range of experimental error, but the Uvicon gave a standard error roughly half that of the Beckman, and about $1.5 \%$ higher $\mathrm{HbF}$ readings. The survey values were not corrected; the data quoted are as measured. The data were analysed both in separate sets and combined into one set; the same results were obtained.

Following the findings of a seasonal variation in $\% \mathrm{HbF}$, a second control series was assessed with the Uvicon water bath at various temperatures in the range $+20^{\circ} \mathrm{C}$ to $28^{\circ} \mathrm{C}$. In keeping with theoretical considerations, no evidence of a temperature related effect was found. All samples with confirmed haemoglobinopathies and chromosomal disorders were excluded from the present study with the exception that $\alpha$ thalassaemia and heterozygous $\beta$ thalassaemia, occurring in the Indo-European and Afro-Caribbean population subgroups, could not be excluded. In this study Indo-European refers to residents with India, Pakistan, or Bangladesh as their country of origin.

Maternal data, hospital registration numbers, and $\% \mathrm{HbF}$ values were input to a computer file and this file was cross-referenced

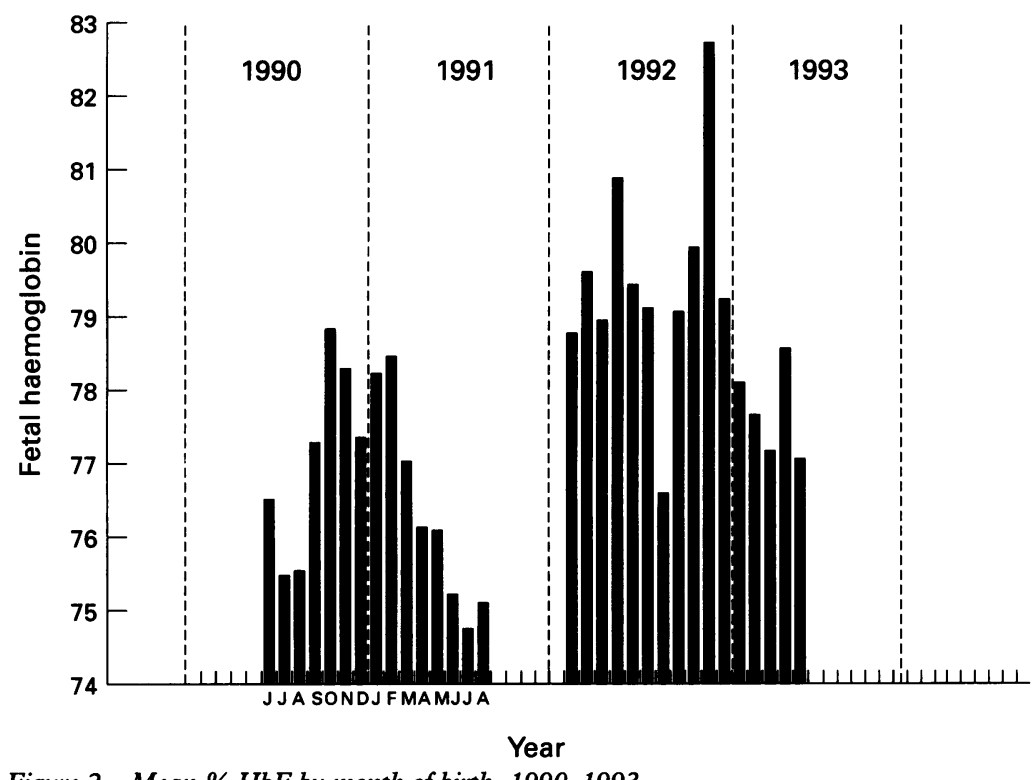

Figure 2 Mean \% HbF by month of birth, 1990-1993. with a larger file supplied by the Department of Obstetrics. This larger file included information on birthweight, ultrasound scan dates, date of delivery, period of gestation, ethnic origin and maternal lifestyle factors during pregnancy. After reviewing the original hard copy records for query matches, records from both computer files were found for 7081 infants and the analysis proceeded on the basis of a new merged file for these infants. Original laboratory $\log$ book entries were reviewed for data points which were outliers: $\% \mathrm{HbF}$ less than $50 \%$; birthweight less than $1.5 \mathrm{~kg}$; and gestation either less than 24 weeks or greater than 42 weeks. A small number of errors were found and corrections were made.

Mean values of $\% \mathrm{HbF}$ were calculated using a number of variables, and the independent importance of these variables was assessed by means of multiple linear regression. The dependent variable was chosen as the logit of $\% \mathrm{HbF}\left(\log _{\mathrm{e}}(\% \mathrm{HbF} /(100-\%\right.$ $\mathrm{HbF})$ ) because the distribution of this variable was much closer to a normal distribution than was the distribution of the untransformed \% $\mathrm{HbF}$. Four categories of ethnic origin were coded in terms of three binary variables. Gestation, birthweight, duration of second stage of labour, and season of birth were treated as continuous variables; season of birth was assessed by the sine and cosine of $\theta$, where $\theta=2 \pi$.(days after 1 January/365).

\section{Results}

Mean \% fetal haemoglobins and associated standard deviations and standard errors for a number of variables are shown in table 1 . The number of infants is relatively large and hence the standard error of the mean is very small; for example, for boys the standard error of the mean $\% \mathrm{HbF}$ is $0 \cdot 12$. It follows that many of the differences between mean fetal haemoglobins, while modest in size, are highly significant. Higher values of $\% \mathrm{HbF}$ were associated with male sex, low birthweight, non-Indo-European ethnic origin, twin delivery and cigarette smoking by the mother during pregnancy. Both maternal use of alcohol and drugs or vitamins were unimportant. Mean \% $\mathrm{HbF}$ was also significantly raised for the second period of data collection for which a new instrument was used. To allow for this, the results were analysed in three groups - old machine results, new machine results, and all together. All the associations remained significant.

Figure 1 shows that, in addition, gestation was strongly associated with $\% \mathrm{HbF}$; preterm births were associated with increased values of $\% \mathrm{HbF}$. Figure 2 shows a seasonal pattern; babies delivered in the winter months had higher values of $\% \mathrm{HbF}$. (This graph also includes data for 1533 births in the period November 1992 to May 1993. These data are not analysed elsewhere in this report and were included here to assess whether the observed seasonality effect is likely to be reliable.) Table 2 shows mean values of $\% \mathrm{HbF}$ (both sexes) by gestation (rows) and by birthweight 
Table 2 Mean \% HbF by gestation and birthweight (both sexes) in 5761 infants

\begin{tabular}{|c|c|c|c|c|}
\hline \multirow{2}{*}{$\begin{array}{l}\text { Gestation } \\
\text { in weeks }\end{array}$} & \multicolumn{4}{|c|}{ Birthweight in $\mathrm{kg}$ (number of infants) } \\
\hline & $<2 \cdot 50$ & $2 \cdot 50-2 \cdot 99$ & $3 \cdot 00-3 \cdot 49$ & $\geqslant 3.50$ \\
\hline $\begin{array}{l}24-25 \\
26-27 \\
28-29 \\
30-31 \\
32-33 \\
34-35 \\
36-37 \\
38-39 \\
40-41 \\
42-43 \\
\geqslant 44\end{array}$ & $\begin{array}{l}94.07(3) \\
90.65(4) \\
89.33(11) \\
88.53(26) \\
85.06(26) \\
86.39(66) \\
83.11(82) \\
79.95(60) \\
78.89(18)\end{array}$ & $\begin{array}{l}76 \cdot 60(3) \\
85 \cdot 43(38) \\
82 \cdot 52(208) \\
79 \cdot 49(470) \\
75 \cdot 54(242) \\
69 \cdot 25(12) \\
76 \cdot 25(4)\end{array}$ & $\begin{array}{l}81.53(8) \\
81.89(119) \\
78.47(850) \\
75.75(1097) \\
73.36(98) \\
73.88(12)\end{array}$ & $\begin{array}{l}81 \cdot 89(28) \\
78.51(481) \\
75 \cdot 18(1469) \\
72.65(313) \\
74.67(9)\end{array}$ \\
\hline
\end{tabular}

(columns). The analysis was restricted to the 5761 infants for whom an ultrasound scan had been performed and both scan date and estimated age of fetus were available. Gestational ages for these infants were obtained by comparing these data with dates of delivery. Within each birthweight group, there is a fairly convincing trend of $\% \mathrm{HbF}$ declining with gestation; within gestation groups trends with birthweight are not as convincing. Fifth and 95th centiles for gestations of 34-35 weeks were $76 \cdot 2$ and $93 \cdot 0$. Corresponding values for gestations of 36-37 weeks, 38-39 weeks, 40-41 weeks, and $42-43$ weeks were $73 \cdot 2$ and $90 \cdot 2,67 \cdot 5$ and $87 \cdot 5$, $67 \cdot 2$ and $85 \cdot 3$, and $58 \cdot 4$ and $84 \cdot 3$, respectively.

The independent importance of these variables was assessed by multiple linear regression. The analysis was restricted to the 5761 infants described above. Table 3 shows regression coefficients (and tests of significance) for variables analysed separately and simultaneously. Gestation was the most important variable in both sets of analyses, although the regression coefficient (absolute value) was somewhat reduced in the 'simultaneous' analysis. Stepwise regression indicated that coefficients for gestation and birthweight were modified by each other rather than by other variables. Regression coefficients for sex, delivery in the second period of data collection, and Indo-European ethnic origin were somewhat increased after simultaneous analysis with other variables. Regression coefficients were little changed for season of birth and much decreased for birthweight, cigarette smoking, twin delivery and duration of second stage of labour. Placental weight and the ratio of birthweight to placental weight were also investigated but found to be unimportant. These two variables were excluded from the above analysis. The above multiple regression analysis was carried out separately for the four ethnic groups to determine whether each group was subject to similar influences. No important differences were found.

\section{Discussion}

The purpose of the multiple regression analysis was to identity which variables were important in their own right and which merely reflected the importance of other variables.

The factors leading to the increase in $\% \mathrm{HbF}$ given in tables 1 and 3 - that is, gestation, birthweight, sex, twinning and maternal smoking are among the most important risk factors for SIDS. ${ }^{9}$

Comparison of the unadjusted (separate) and adjusted (simultaneous) regression coefficients for maternal smoking and $\% \mathrm{HbF}$ increase suggest that about half of the smoking effect operates via reduced birthweight and shorter gestation and that the other half is a residual additional effect. This is closely similar to the findings of several SIDS epidemiological studies ${ }^{10}$ which suggest that there was still a residual excess risk of SIDS in the infants of antenatal smoking mothers after the effects of prematurity and low birthweight had been taken into account.

A similar but lesser effect is seen in twin deliveries where some $80 \%$ of the twin effect $(0.444-0.093) / 0 \cdot 444=0.79)$ on $\% \mathrm{HbF}$ could be explained by gestation, birthweight, and the other variables, leaving a definite residual effect. Interestingly, data collected on twin pregnancies and SIDS $^{9}$ also suggested a residual excess risk after the effects of weight and gestation were accounted for.

Alcohol consumption, diet and prescribed drug and vitamin intake have not been shown to carry any SIDS excess risk implication, and similarly we found no effect of these factors on $\% \mathrm{HbF}$.

Table 3 Results of regression analysis

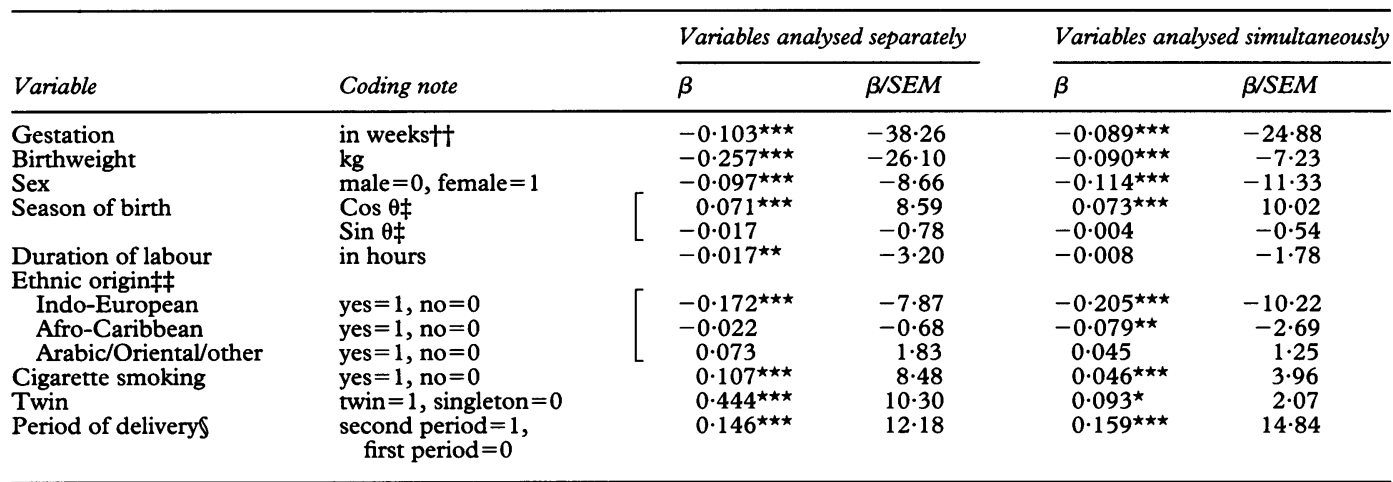

Dependent variable is logit $(\% \mathrm{HbF})$ and regression coefficients $(\beta) \dagger$ are shown for independent variables analysed both separately (linear regression) and simultaneously (multiple linear regression) for 5761 infants.

The regression coefficient is the slope of the regression line and estimates the change in logit (\% $\mathrm{HbF}$ ) per unit change in the dependent variable, eg, in the simultaneous analysis, logit $(\% \mathrm{HbF})$ is decreased by 0.089 for an increase in gestation of one week and decreased by 0.090 for an increase in birthweight of one kg. HRecorded to two decimal points.

$\neq \theta=2 \pi$.(days after 1 January/365). $\neq \neq$ Caucasian is coded as zero for all three binary variables.

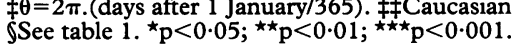


The lower values of $\% \mathrm{HbF}$ associated with Indo-European ethnic origin were not, according to the multiple regression analysis, explicable in terms of birthweight or gestational differences. It is unlikely that carrier status for $\alpha$ thalassaemia is the sole reason for these lower values, and some lifestyle factor is probably responsible. Alternatively, there may be a true genetic effect.

One novel finding from this analysis is that season of birth was associated with \% $\mathrm{HbF}$. This finding is not a result of confounding by the other variables. Birthweight, for example, was unrelated to month of birth (mean birthweight $=3.3 \mathrm{~kg}$ for 10 of the 12 months) and could not, therefore, have produced such an effect. Findings from the second (and third) periods of data collection are not as convincing as those from the first, and it will be important for this finding to be replicated in other studies.

The size of the independent effect of variables on $\% \mathrm{HbF}$ may be assessed by comparing the values of the adjusted regression coefficients. Similar influences are exerted by differences in gestation of one week, birthweight of $1 \mathrm{~kg}$, date of birth of three months, as well as sex of infant and twin delivery. About double this effect is associated with IndoEuropean ethnic origin. For infants born near to 40 weeks' gestation, the 'influence' of an additional one week of gestation is a lowering of $\% \mathrm{HbF}$ by about $2 \%$.
Findings for sex, gestational age, and birthweight are consistent with those reported by Galacteros et $a l^{6}$ for \% $\mathrm{HbA}$ in newborn infants; factors associated with higher values of $\% \mathrm{HbF}$ in the study reported here were associated with lower values of $\mathrm{HbA}$ in the French study.

We are grateful to the Foundation for the Study of Sudden Infant Deaths for funding this study. We also pay tribute to the enthusiasm and cooperation of the midwives in the Departmen of Obstetrics for taking samples, and thank the Division of Obstetrics for making the maternal data freely available. Our special thanks go to Dr P Maynard, who enabled the computers to talk to one another.

1 Giulian GG, Gilbert EF, Moss RL. Elevated fetal hemoglobin levels in sudden infant death syndrome. $N$ Engl $\mathcal{F}$ Med 1987; 316: 1122-6.

2 Fagan DG, Walker A. Haemoglobin F values in sudden infant deaths. $\mathrm{Br} \mathcal{F}$ Haematol 1992; 82: 422-30.

3 Huehns ER, Beaven GH. Developmental changes in human haemoglobins. Clin Devel Med 1971; 37: 175-203.

4 Wood WG, Clegg JB, Weatherall DJ. Developmental biology of human haemoglobins. In: Brown EB, ed. Progress in Haematology 10. Philadelphia: Grune and Stratton, 1977: 43-90.

5 Stamatoyannopoulos G, Nienhuis AW. Hemoglobin switching. In: Stamatoyannopoulos G, Nienhuis AW, Leder P, Majerus $\mathrm{P}$, eds. The molecular basis of blood diseases. Philadelphia: WR Saunders, 1987: 66-105.

6 Galacteros F, Guilloud-Bataille M, Feingold J. Sex, gestational age, and weight dependency of adult hemoglobin concentration in normal newborns. Blood 1991; 78: 1121-4.

7 Walker J, Turnbull EPN. Haemoglobin and red cells in the human foetus III. Foetal and adult haemoglobin. Arch Dis Child 1955; 30: 111-6.

8 Jonxis JHP, Huisman TJH. A laboratory manual on abnormal haemoglobins. 2nd edn. Oxford: Blackwell Scientific haemoglobins. 2nd

9 Gibson, AAM. Current epidemiology of SIDS. $f$ Clin Pathol 1992; 45 (Suppl): 7-10.

10 Gilbert R. Smoking, alcohol and drug use. Current Paediatrics 1992; 2: 215-6. 